\title{
Electrochemical Determination of Cancer and Cardiovascular Biomarkers Based on Advanced Screen-printed Immunosensors
}

\author{
Zhibo Li ${ }^{1, *}$, Li Geng $^{2}$, Tao Feng ${ }^{2}$, Jing Wang $^{2 *}$ \\ ${ }^{1}$ The second hospital of Jilin University, Jilin, 130012, P.R. China \\ ${ }^{2}$ Central Hospital of Changchun, Jilin, 130121, P.R. China \\ *E-mail: zhiboli_jilin@yahoo.com louis1014@sina.com
}

doi: $10.20964 / 2016.11 .41$

Received: 13 August 2016 / Accepted: 11 September 2016 / Published: 10 October 2016

\begin{abstract}
Screen-printed electrodes (SPE), previously widely used in the design of disposable sensors, has recently attracted considerable interest for the application in electrochemical immunosensors for fieldclinical analysis. For the sake of increasing the sensitivity of SPE for the determination of cardiac troponin $\mathrm{T}(\mathrm{cTnT})$ which is a specific biomarker for the acute myocardial infarction diagnosis, graphene was incorporated to the SPEs in this study. Differential pulse voltammetry (DPV) with ferrocyanide/ferricyanide redox probe was employed for the determination of cTnT after the electrode was incubated in the cTnT solution. The current response was related linearly with the concentration of cTnT ranging from $0.01 \mathrm{ng} / \mathrm{mL}$ to $1 \mathrm{ng} / \mathrm{mL}$ with correlation coefficient of 0.995 . The obtained limit of detection (LOD) of $0.005 \mathrm{ng} / \mathrm{mL}$ was lower than previously reported immunosensors and comparable with conventional analytical techniques. The proposed immunosensor exhibited high sensitivity, good reproducibility, high stability and clinical range, demonstrating the potential application in point-ofcare diagnose of acute myocardial infarction.
\end{abstract}

Keywords: Electrochemistry; Immunosensor; SPE; cTnT; Graphene

\section{FULL TEXT}

(C) 2016 The Authors. Published by ESG (www.electrochemsci.org). This article is an open access article distributed under the terms and conditions of the Creative Commons Attribution license (http://creativecommons.org/licenses/by/4.0/). 